\title{
СОВРЕМЕННЫЙ ВЗГЛЯД НА МОДЕЛЬ ПСИХИКИ ЧЕЛОВЕКА В ТВОРЧЕСТВЕ И. КАНТА
}

\section{A MODERN VIEW ON THE MODEL OF HUMAN PSYCHE IN THE WORKS OF I. KANT \\ V. Kryukov}

Summary: This article provides an overview of the problems posed in the philosophical works of I. Kant, in particular, the analysis of «Critique of Pure Reason» by I. Kant, a modern philosophical view of Kant's ideas about the model of the human psyche, as well as his understanding and description of the work of the subconscious.

Keywords: criticism of pure reason, Kant, materialism, Pure Reason, Practical reason, Artificial Intelligence.

\author{
Крюков Владимир Германович \\ Д.nсх.н., Western Kennedy University \\ infomodelpsi@mail.ru
}

Аннотация: В данной статье проведён обзор поставленной проблематики В философских трудах И. Канта, в частности, анализ «Критики чистого разума» И. Канта, дан современный философский взгляд на идеи Канта о модели человеческой Психики, а также на понимание и описание им работы внутренних механизмов принятия решений.

Ключевые слова: критика чистого разума, Кант, материализм, Чистый Разум, Практический разум, Искусственный Интеллект.
A нализ «Критики чистого разума» Канта, свидетельствует о том, что Интеллект или Чистый разум как таковые понятия были описаны Кантом в его творчестве. Кант описал модель Психики человека, а его Чистый Разум есть ничто иное как Искусственный Интеллект в современном его понимании, что мы и попытаемся доказать в рамках данной статьи.

Разобраться в «Критике чистого разума» пытались многие философы. За рассуждениями о трансцендентальной метафизике и спорах о познании, априори, философы скрывали свое непонимание даже основного термина «Вещь с себе». Занимаясь философской эквилибристикой терминов и понятий, уважаемые философы не разглядели простую цель Канта - описать устройство и работу Психики человека.

Обзор поставленной проблематики в философских трудах Канта нельзя считать полным. Однако, проанализировав диссертации этого века и работы классиков, в частности, А.Шопенгауэра [6] или М. Хайдеггера[5], можно утверждать, что никто из рассмотренных авторов не смог сформулировать реальную цель работы Канта, несмотря на то, что Кант сумел свести воедино идеализм и материализм, объяснив работу Психики.

Внешний мир материален, а Психика идеальна. И как они взаимодействуют друг с другом, подробно рассказал Кант.

Идея Канта заключается в том, что во внешнем мире действует материализм с объективными законами, а внутри - идеализм, который старается построить свою, субъективную картину мира для каждой особи. И эти две реальности прекрасно соседствуют и не противоречат друг другу. Отсутствие необходимого авторитета в философии не позволяет мне утверждать эту мысль, однако считаю свои правом вынести её на обсуждение.

Начнём с известного многим понятия «Вещь в себе». Философы давали свое понимание, но мнения разделились. Что же понимал под этим сам Кант? Он не давал четкого и ясного определения этого понятия, но точно разделял внешние явления и их внутреннее отражение в Психике, которое как раз и является вещью в себе. То есть, в современной терминологии «Вещь в себе» есть ничто иное как внутренний образ внешнего объекта, который преобразуется в Психике посредством наших органов восприятия. Это ключевое определение Канта, которое объясняет его идею. Что прекрасно соотносится с действительной картиной реального мира.

Ниже мы проанализируем словесную конструкцию Канта и дадим подробные пояснения основной идеи Канта:

«Ошущение есть действие предмета на нашу способность представления, по мере того как мы получаем от него впечатления. Наглядное представление называется опытным, если оно посредством ощущения имеет дело с внешним предметом. Я называю те представления чистыми (в трансцендентальном рассудке), в которых не встречается ничего относящегося к ощущениям. Поэтому чистая форма наглядных представлений находится в душе априори, и в ней мы наглядно представляем себе содержание явлений в известных отношениях. Эта чистая форма чувственности называется чистым наглядным представлением» [3].

Философы видят в идее Канта о внутренних образах 
повод для дискуссии об идеалистической направленности теории Канта, однако это слишком простое объяснение работы нашей Психики: именно того, что происходит у каждого в душе, и каждый имеет возможность это наблюдать. Но мало кто обращает внимание на элементарные и очевидные «вещи, которые находятся в себе». Кант сумел это не просто увидеть, но и осмыслить.

Кант прекрасно разбирался в естественных науках, а знания о Психике чаще всего отвергают представители точных наук, считая их случайными процессами, не поддающимися логическому изучению. И, в лучшем случае, применяют вероятностные модели, так как не способны разглядеть закономерности в работе Психики. Кант обнаружил эти закономерности, назвав их максимы.

Изучая работу Канта в рамках данной статьи, мы искали модель человеческой Психики и описание работы подсознания. И находим именно систему Разума, причём Кант был абсолютно уверен в ее детерминированности, а не вероятностной случайности, как полагают многие. Случайность - это до сих пор не понятая закономерность, которую автор данной статьи полностью разделяет и подтверждает открытия Канта, значительно опередившие свое время. Накопленные классиками психоанализа знания о Психике полностью соответствуют тому, что описывал Кант.

В рамках психологии придуманы механистические модели, однако не выстроена система. Однако всеобщее понимание того, что Психика - это некая система, присутствует, только вот как устроена эта система до конца не понятно. Даже сам Юнг на исходе жизни пытался в своей книге «Синхроничность»[7] построить некую систему, однако не получилось. В его работах, к сожалению, не встречается ни одного упоминания идей Канта.

Сейчас многие в качестве аналога сравнивают Психику с компьютером. Это стало модно, однако мы здесь видим обратную аналогию. Компьютер - очень упрощённая модель Психики. Его, скорее, сделали по образу и подобию нашего мышления. Архитектуру компьютера придумал фон Нейман, хотя теоретическое обоснование создал Тьюринг. Никакого опыта, то есть, познания апостериори, на тот момент не было. Значит, это результат работы его чистого разума или, другими словами, плод его интеллекта, производное Психики. Да и программы пишутся исключительно Психикой программистов.

Была ли во времена Канта теория систем? Начиная читать «Чистый разум», сталкиваемся со следующим текстом: «В самом деле, средства, способствующие ясности, помогают пониманию отдельных частей, но нередко отдаляют понимание челого, мешая читателю быстро обозревать челое, и своими слишком яркими красками затемняют и скрадывают расчленение или структуру системы, между тем как именно от структуры системы главным образом и зависят суждения о ее единстве и основательности». То есть, Кант собирается применить Системное Мышление к пониманию Разума. Ведь такая фраза отражает принцип Системного мышления, описанный в любом учебнике.

Кант выстраивал целостную систему Чистого Разума. Можно сказать, что он просто запечатлел на бумаге свои мысли и идеи относительно системы Психики, хотя вопрос пользы от этих знаний для остальных людей его мало интересовал.

Рассмотрим построение этой системы, которую стремился выстроить Кант. Забегая несколько вперёд, хочется заметить, что целостной системы у Канта не получилось, так как он озадачился традиционным для психологии вопросом целеполагания работы Психики. На вопросы, что является критерием оценки в деятельности Психики, почему принимается то или иное решение, и почему при одинаковых внешних условиях принимаются разные решения, Кант не нашёл внятного, точного ответа и дал повод философам на протяжении веков вольно трактовать и обсуждать его идеи.

А такой ответ есть. Только надо соединить Системотехнику и Психоанализ в единое множество знаний.

Кроме того, вопрос чувственности и эмоций был недостаточно прояснен Кантом, по причине ограниченности знаний в этой области психологии, даже, скорее всего, полного отсутствия практической работы с реальными пациентами. В его время знания о Психике были в зачаточном состоянии, хотя при этом Кант сделал гениальные догадки о строении и работе Психики, опередившие доказательную науку на пару столетий. И самое главное, Кант сумел понять структуру и принципы работы Разума.

Ещё одна проблема проистекает из нежелания Канта сделать свои идеи доступными для понимания широкого круга читателей. При изучении его работы складывается ощущение, что Кант сам до конца не понимал некоторые моменты и писал интуитивно, из души. Вопросы, непосредственно относящиеся к психологии, выглядят весьма путаными, потому что ответы он ощущал «на кончиках пальцев». Следующие поколения исследователей стали гораздо четче разобраться в чувственности и ощущениях.

Можно утверждать, что Кант просто записывал свой поток размышлений, не стремясь при редактировании текста упростить его понимание для читателя, а также предположить, что он писал в Будущее, что вполне возможно, учитывая неординарность его личности и нереализованное либидо. Ведь давно известно, что неиспользуемая сексуальная энергия может быть использована 
для «Просветления духа», как в монашестве, например, однако, это утверждение нельзя доказать за истечением срока давности.

Понимание написанного Кантом начинает проясняться, когда мы применим к его работам современные знания психологии вкупе с системным мышлением. Сам Кант наталкивает нас на эту мысль в предисловии «Критики практического разума».

«Если читатели указанной книги знают более популярные термины, которые столь же соответствуют мысли, как соответствовали, по моему мнению, употребляемые мною термины, или надеются доказать ничтожность самих этих мыслей, а значит, и каждого обозначающего их термина, то в первом случае я буду им очень обязан: ведь я хочу только одного - быть понятым, а во втором они окажут услугу философии».

Приходится искать нынешнее соответствие понятным терминам. Разработаем приблизительную таблицу соответствия терминов Канта и современных понятий, что и приближает к пониманию тех мыслей и идей, которые сокрыты в текстах Канта:

- Чистый Разум - мышление или интеллект, составляющий исключительно внутреннюю работу Психики (это и есть априори)

- Практический Разум - рефлекторная или неосознанная работа Психики, выражающаяся в непосредственных реакциях организма на внешние воздействия. Основана на опыте. (апостериори). Чаще всего, реакции физиологические, происходят без участия сознания. Это основа когнитивной психологии.

- Вещь в себе - объединенный внутренний образ в Психике, отражающий внешний объект реального мира. Кстати, Кант не считал их тождественными, что в точности соответствует нашей действительности и современным взглядам.

Априори, в Кантовском смысле, - созданное мышлением из обработки внутренних образов, теоретическая обработка образов, явлений и событий. Апостериори полученное в результате действий и опыта. (Визуальное мышление очень похоже на практический разум, возникающий апостериори). К этому понятию относятся рефлексы, паттерны, стандартные программы, то есть все, что не использует мышление.

- Воля - принятие решения. Свобода воли - принципы и анализ принятия решений.

- Суждения - анализ и основания для принятия конкретного решения.

- Нормы морали и этики - обработанный разумом человечества опыт, преобразованный в устойчивые закономерности разума, названные Кантом максимами.
Таким образом, переводя со сложного языка понятий Канта на доступный современникам язык, по-другому улавливаются мысли и размышления Канта. Обладая огромными знаниями в психоанализе, прочитав труды знаменитых классиков этой не менее сложной науки (Фрейд [4], Юнг[7], Адлер[1], Фромм, Маслоу, Берн, Райх, Лоуэн, Хорни), приходим к удивительному выводу, что Гений Канта опередил развитие психологии на полтора века вперед, а системы Искусственный интеллект более чем на два с половиной.

Современная когнитивная психология затрудняется понять методы познания Психики, а все искомые ответы подробно расписал Кант еще в восемнадцатом веке, несмотря на то, что в психологической литературе нет даже упоминания имени Канта и ссылки на него.

\section{Модель психики Канта}

Проанализируем, какую же систему психики хотел построить Кант:

«Я надеюсь построить такую систему чистого (сnекулятивного) разума под названием «метафизика природы». «Что это вообще возможно и что такая система не будет весьма обширной и, следовательно, можно надеяться со временем кончить ее, можно заключить из того, что в ней будет трактоваться не о природе бесконечного множества вещей, но о рассудке, который обсуждает их, да и о нем в той мере, в какой он способен к познаниям априори».

В переводе на современный язык, система будет работать не с неограниченным количеством объектов внешнего мира, а со значимыми внутренними образами. Эти внутренние образы созданы Психикой и отражают качества внешних объектов.

По словам Канта, «ощущение есть действие предмета на нашу способность представления, по мере того как мы получаем от него впечатления. Наглядное представление называется опытным, если оно посредством ощущения имеет дело с внешним предметом. Я называю те представления чистыми (в трансцендентальном рассудке), в которых не встречается ничего относящегося к ошущениям. Поэтому чистая форма наглядных представлений находится в душе априори, и в ней мы наглядно представляем себе содержание явлений в известных отношениях».

В переводе на современный язык, ощущение - это реакция наших «сенсорных датчиков» на внешние физические воздействия; впечатления - это ассоциации, которые связаны с внешним объектом. Они свойственны только реальной субъективной Психике. Внутренний образ для ИИ не должен содержать ничего субъективно- 
го, относящегося к конкретной Психике. То есть, он универсален или идеален по Канту. Внутренний образ создается самой Психикой в процессе познания внешнего объекта.

В реальном мире есть миллиард кошек, но образов кошки в Психике гораздо меньше, а для внутреннего анализа мы и вовсе используем один собирательный образ кошки. Это Кант и назвал «Вещь в себе». В реальном мире их не существует. Вещь в себе располагается только в Психике и служит исключительно для ее работы. Анализ, проведённый в данной статье, позволит этот термин наполнить правильным содержанием.

\section{Познание Канта}

Попытаемся разобрать мысль Канта о познании:

«Всякое познание следует за опытом и с ним начинается. Разум есть такая способность, которая дает нам принципы познания априори. Следовательно, чистый разум содержит в себе принципы познания безусловно априори. Органом чистого разума можно назвать сумму тех принципов, по которым могут быть приобретаемы и осуществляемы все чистые познания априори».

Основой и началом познания служит опыт. Но сами познания рождаются в Психике, в процессе обдумывания пережитого опыта. Не опыт сам по себе даёт познание, а его создает мышление или Чистый Разум. Опыт может сформировать автоматический рефлекс, как, например, реакция на удар током. Но это не познание, а паттерн или программа на выходе системы. Познание возникает, когда мы обдумали этот удар током и приняли для себя внутренний закон: не надо хвататься за оголенный провод. И Кант это безусловно закрепляет. Чистый разум содержит только продукты работы Психики (априори). И совокупность этого обработанного опыта и есть содержание Чистого Разума.

Для более четкого понимания объясним наш взгляд на модель Психики, которая актуальна в XXI веке. «Информационная модель Психики» объясняет все процессы, происходящие в нашем сознании и бессознательном. Итак, из внешнего мира на человека оказывается физическое и химическое воздействие. В окружающем нас пространстве мы видим объекты. Это световые волны, исходящие от них. Аналогично и со звуковым волнами, которые «передают мысли». Организм воспринимает физические воздействия, аналогично сенсорным датчикам. А теперь посмотрим в оригинале XVIII века.

«Эта наука расчленяет все наше познание априори на составные части. Она обращает внимание на следуюшие вещи:

1. понятие должны быть чистыми, а не опытными;
2. они не должны относиться ни к представлению, ни к чувственности, но только к мышлению и рассудку;

3. они суть основные понятия и должны быть отличаемы от выводных и сложных;

4. перечень ихдолжен быть совершенно полный и обнимать целую деятельность чистого рассудка. Такая полнота науки не может быть достигнута посредством беглого обзора случайно сведенных вместе понятий; она возможна только тогда, когда мы овладеем идеей челого познания разума априори и на основании ее разделим входящие в него понятия, следовательно, когда мы соединим их в системе. Чистый рассудок не имеет никакого дела не только с чем-нибудь опытным, но и со всякой чувственностью».

Можно считать, что это подробная инструкция для создания Искусственного Интеллекта. В нашей теоретической Системе ИИ есть библиотека Внутренних образов, в которой и собирается познание о внешних объектах. И у Канта четко сформулировано, не допуская иных трактовок, - познание есть работа мышления с чистыми понятиями без всяких субъективностей, наполняющих реальную Психику.

Представлю несколько цитат, которые теряются в потоке сложносочиненных предложений, коими изобилуют тексты Канта. Намеренно или случайно Кант затруднял свои тексты, мы не узнаем. Можно предположить, что так работала его гениальная Психика. Рассмотрим оригинал и дадим комментарии.

«Познание есть нечто целое, состоящее из анализованных и объединенных представлений». Познание - не опыт, а результат обработки опыта мышлением, производное Психики.

«Рассудок есть способность познания». Подтверждает предыдущий тезис.

«Мыслить предмет и познавать его - две вещи совершенно различные».

«Рассудок не может представлять, чувство - мыслить».

«Поэтому тщетны все попытки вывести из опыта чистые понятия рассудка и доказать их чисто опытное происхождение».

Разделение процесса познания и получения опыта много раз повторенная идея Канта. Современные когнитивисты не видят этого различия и сводят эти понятия воедино, выставляя практический опыт во главе процесса познания. Однако, таким способом можно лишь автоматизировать только процесс, поддающийся формализации, а никак не Интеллект. Чтобы научить кого-то мыслить, нужно сначала понять, что это за процесс Мыш- 
ления. Именно это и было главной целью работы Канта.

\section{Пространство и время}

Исходя из того, что материальная реальность отражается в нашей Психике в виде внутренних образов, Кант не мог обойти вопрос времени и пространства. Очевидно, что объекты реального мира существуют во времени и пространстве. Это ни у кого не вызывает возражений. Но сами эти категории определены и объяснены вроде бы весьма расплывчато. Проанализируем цитаты Канта: «время есть нечто действительное, именно как действительная форма внутреннего представления» и «время есть не что иное, как форма внутреннего чувства, т. е. созерцания нас самих и нашего внутреннего состояния».

Приведена одна и та же формулировка из разных переводов текста на русский язык, чтобы показать, что следствием трудности понимания исходного текста переводчиками является разная трактовка смысла.

«Пространство и время суть чистые формы его [чистого разума], а ошущение вообще есть его материя. Пространство и время мы можем познавать только а priori [внутри Психики], т.е. до всякого действительного восприятия, и потому они называются чистым созерцанием; ощущения же суть то в нашем познании, благодаря чему оно называется апостериорным познанием, т. е. эмпирическим созерцанием. Пространство и время безусловно необходимо принадлежат нашей чувственности, каковы бы ни были наши ощущения; ощущения же могут быть весьма различными».

Это самое главное определение Канта для понимания его системы Чистого Разума. Пространство и время производное Психики. За это философы считают Канта идеалистом, хотя он абсолютный реалист.

В реальном мире есть только текущий момент, никакого прошлого или истории в природе уже нет. Прошлое есть только в нашей Психике в виде воспоминаний. В реальном мире есть только «Сейчас». Причинно-следственные связи есть, но нет прошедшего времени. Мы можем попасть «во вчера» только в работе своей Психики.

Мы не можем в реальности оказаться ни в прошлом, ни в будущем. Вернее, в будущем мы обязательно окажемся, но только тогда, когда оно станет «Сейчас». Только в своей Психике мы имеем воспоминания и смотрим в будущее. Только в Психике мы анализируем прошедшее с целью создания закономерностей и познания. Это Кант и называл априори.

Мы моделируем будущее с целью построения планов. Но практически никогда наши надежды не сбывают- ся. Объективный мир реальности изменяется в каждый следующий момент времени, поэтому мы не в состоянии точно предсказать, каким мир будет в будущем.

Мы можем намечать планы и осуществлять целенаправленную деятельность, но все равно получается чуть по-другому, не так как намечали. Это не только потому, что мы строим «плохие» планы, а потому что не можем смоделировать все реакции реального мира на наши действия. То есть, учесть весь объем данных от обратной связи при моделировании принципиально невозможно, так как невозможно рассчитать весь окружающий мир.

Наши познания о пространстве основаны на том, что мы видим вокруг себя. Когнитивисты называют это визуальным мышлением. Остальное представление о пространстве есть чьи-то мысли и гипотезы, то есть плод работу чьего-то мышления. Ни один человек не был на Mapсе, не мог видеть ничего вживую. Но люди имеют теоретическое представление об этой планете, только все время спорят о том, чего не знают достоверно.

Проанализируем мнение Канта, относящиеся к понятию пространства.

«Пространство не есть эмпирическое понятие, выводимое из внешнего опыта». «Представление о пространстве не может быть поэтому заимствовано из отношений внешних явлений посредством опыта: сам этот внешний опыт становится возможным прежде всего благодаря представлению о пространстве».

Но споры о пространстве и времени будут вечными. Я же склоняюсь к пониманию Канта этих явлений.

Ранее мы намеренно не использовали в этой статье современный термин «Информация», поскольку во времена Канта его не существовало. И как только мы станем применять его к работе Канта, то все сразу станет на свои места. Пространство и время - лишь Информация в Психике.

\section{Почему Кант разделил Психику на Чистый и Практический Разум}

Современные исследователи рассуждают о сознании, об осознанности, спорят о познании и его методах. Хорошо известно, что наука - история заблуждений. Современные «мыслители» додумались до мышечной памяти, визуального мышления. А что управляет всем этим? Разве что костный мозг. В современной психологии много разных направлений. Некоторые копируют друг друга. Например, гештальт-терапия является, по сути, упрощённым психоанализом. НЛП и гипнотерапия - направления, различающиеся только методом приведения пациента в состояние, пригодное для внушения. 
Однако целостного понимания работы Психики до настоящего времени нет. Знаний апостериори накоплено много, а чистого разума априори для обдумывания всего объёма информации о Психике не хватает.

\section{Почему же Кант разделил Психику на две части?}

«Аналитика чистого теоретического разума имела дело с познанием предметов, которые могут быть даны рассудку; следовательно, она должна была начинать с созерцания; стало быть (так как это созерцание всегда чувственно), с чувственности, только от них перейти к понятиям (предметов этого созерцания) и, лишь предпослав то и другое, могла завершиться основоположениями. Практический же разум имеет дело не с предметами с целью их познания, а со своей собственной способностью осуществлять эти предметы (сообразно с их познанием)». Исходя из его концепции времени, можно предположить, что Практический Разум работает в текущем моменте времени. То есть, это автоматическая, рефлекторная деятельность, как немедленная реакция на внешнее воздействие. А Чистый Разум - это мышление, анализ прошлого или моделирование будущего, но только не работа сейчас. Два взаимодополняющих компонента нашей Психики. Поэтому реальные объекты связаны с текущим моментом и принятием сиюминутного решения, а в работе чистого разума используются внутренние образы в виртуальном пространстве и времени, то есть моделируются возможные ситуации и потенциальные решения.

Когнитивная психология, которую проповедуют IT специалисты, признает только опыт, как реакцию Психики на внешнее воздействие. То есть, это есть Практический разум. А Интеллект, как понимал его Кант, это Чистый разум. Ответив на вопрос, как связать воедино Чистый и Практический Разум, станет возможным создание системы ИИ.

Кант много внимания уделил рассмотрению работы Практического разума. А именно, в современной терминологии, он рассмотрел систему принятия решений, на которой мы далее остановимся.

\section{Принятие решений}

Во времена Канта еще не существовало терминов рефлекс, инстинкт, паттерн или программа, которые вошли в нашу научную лексику лишь в XX веке. То, что мы под этим понимаем, он назвал максима. А также Воля для Канта - это принятие решения.

«Воля как способность желания есть именно одна из многих физических причин в мире, а именно та, которая действует по понятиям; и все, что можно представить себе как возможное (или необходимое) через волю, назы- вается практически возможным (или необходимым), в отличие от физической возможности или необходимости действия, где причина определяется к причинности не через понятие (в бездушной материи через механизм, ауживотных через инстинкт)».

Ну, за понятия мы говорить не станем. И кто по понятиям, Кант или переводчик, непонятно.

Понимание рассуждений Канта о воле, свободе воли, морали и этики подтверждает, что до неосознанного или бессознательного Кант не добрался. Они были объяснены Фрейдом. А значит все написанное может восхищать лишь запутанностью понятий и теорем. Возможно, сам Кант разбирался в своём нагромождении умных мыслей, идей и блестящих выводов. Решения ИИ нужно искать в несколько иной плоскости. Далее мы обозначим эти задачи.

«Суть всякой нравственной ценности поступков состоит в том, что моральный закон непосредственно определяет волю. Если определение воли хотя и совершается сообразно с моральным законом, но только посредством чувства».

На принятие решения влияет обобщенный опыт (моральный закон). Но и внутреннее отношение к образу объекта также оказывает влияние. Каждый из нас знает, как много надо учесть при принятии правильного решения. Кант пытался разобраться и объяснить «Свободу воли» через нормы морали и понимание ценности последствий. Но в этом вопросе запутался не он один, а многие признанные мыслители. Только применив системное мышление можно разрешить эту запутанность Психики.

Вопросам морали и этики посвящено несколько исследований в психоанализе. Адлер [7[ и Фромм задавались вопросом, как принимаются решения, и что служит реальным критерием выбора., и нашли очень разумные ответы.

Нам постоянно приходится отвечать на вопрос, почему я принимаю не те решения, которые нужны. Особенно это проявляется в женской сексуальности. Заглянув в подсознание, и проанализировав истинные причины, приходит понимание того, как принимаются решения в Психике.

Пользуясь вышеизложенными рассуждениями, системный аналитик, может выстроить Систему человеческого Интеллекта.

Основные составляющие:

1. Практический Разум - текущее решение. Чистый Разум - мышление, интеллект (анализ и модели- 
рование).

2. Время в реальном мире - существует только сейчас. Поэтому система должна уметь принимать решение здесь и сейчас. То есть, научившись обрабатывать один такт, система будет обрабатывать всю последовательность, впрочем, как и любая другая автоматическая система. И не столь важно, реальное время или виртуальное.

Как писал Кант, «характер - практически последовательный образ мышления по неизменным максимам».

3. Мышление - последовательность текущих решений. Последовательность, направленная в прошлое, да в обратном порядке это анализ. А последовательность решений, устремленная в будущее, есть моделирование и прогнозирование.

4. Опыт - стандартное правильное решение, полученное ранее «апостериори». Опыт бывает личный и общечеловеческий. И то, и другое формируется поиском закономерностей.

5. Внутреннее состояние системы определяет принятие того или иного решения. В каждом такте внутреннее состояние изменяется. (Но не по вероятностной модели Маркова).

6. Глобальная цель системы неизменна, а локальные цели постоянно меняются в зависимости от внутреннего состояния и внешних воздействий. Это приводит к иерархии целей.

\section{Понимание шелей человека}

Создать систему без понимания целей невозможно. "Все материальные практические принципы как таковые суть совершенно одного и того же рода и подпадают под общий принцип себялюбия или личного счастья".

Это попытка Канта найти оценку или критерий для принятия решений. Над этим заставляли работать свои головы многие великие мыслители, однако философия не нашла внятного ответа, погрязнув в многочисленных вариантах и бесконечных спорах о целях бытия.

Можно согласиться с мыслью А. Адлера, что ценность человека определяется его способностью к выживанию, так как выживание и воспроизводство - единственные биологические задачи человека [1]. Все остальное лишь их производное. Собственно для обеспечения выживания мы и накапливаем опыт. И уж совсем очевидно, что более опытный человек более ценен.

Кант по этому поводу писал так: “Сознание приятности жизни у разумного существа, постоянно сопутствующее ему на протяжении всего его существования, есть счастье, а принцип сделать счастье высшим, определяющим основанием произвольного выбора есть принцип себялюбия".
"Все материальные практические правила полагают определяющее основание воли в низшей способности желания, и если бы не было чисто формальных законов ее, которые в достаточной мере определяли бы волю, то нельзя было бы допустить и какую-либо высшую способность желания".

Желание - это цель, а воля - принятие решения.

Кантзадавалсяэтимивопросами,почемупринимается решение, что оказывает влияние, но, несмотря на знание математики, оцифровать эту задачу даже не пытался. А найти решение в рамках субъективных оценок "лучшехуже" в принципе невозможно.

Кант упоминал внутреннее состояние, но не связал это непосредственно с принятием решений. Связав эти два понятия, можно найти ключ к системе интеллекта.

“Каким образом можно было бы сравнивать величину двух определяющих оснований, совершенно различных по способу представления, чтобы предпочесть ту, которая больше всего воздействует на способность желания?"

\section{Опрехеление чели принятия решений}

«Сиастье - это такое состояние разумного существа в мире, когда все в его существовании происходит согласно его воле и желанию; следовательно, оно основывается на соответствии природы со всей его челью и с главным определяющим основанием его воли».

«Все душевные силы или способности могут быть сведены к трем, которых уже нельзя вывести из общего для них основания; это познавательная способность, чувство удовольствия и неудовольствия и способность желания».

Разбираться в логических построениях последней части трилогии достаточно сложно. Наиболее ценным в нагромождении разнообразных причин свободы воли нам показалось понимание термина максима.

Максима воли и есть причина принятия решения. Выстроить Систему принятия решений у Канта не получилось, что абсолютно закономерно для уровня знаний о Психике той далёкой эпохи, несмотря на это его тексты открывают глаза на понимание устройства Психики.

\section{Зак^ючение}

В «Критике чистого разума» Кант строит модель Искусственного Интеллекта, но описывает её в рамках своей терминологии. Там содержится много гениальных откровений, однако, многие вопросы вскрываются лишь поверхностно. Кант пытается описать 
практические принципы работы Психики. Исследует основания для принятия решений, пытаясь определить что формирует волю. Нравственные или иные законы, опыт или инстинкт. Вопросы подняты и поставлены, но, несмотря на обилие расплывчатых и неоднозначных ответов, чёткой картины не вырисовывается. Следует отметить, что Кант наметил основную идею обработки опыта, однако, не сумел её ясно сформулировать. Нравственные и моральные зако- ны - это «сжатый» опыт человечества.

В «Критике способности суждения» Кант ищет критерии для анализа работы Психики, в целом, и принятия решений, в частности. Он пытался применить математический способ мышления, однако необходимо сказать, что точные математические ответы не найдены. Для этого нужно применить системно-информационный подход к Психике.

\section{ЛИТЕРАТУРА}

1. Адлер А. Практика и теория индивидуальной психологии. СПб.: Питер, 2017

2. Кант И. Критика способности суждения. М.: Искусство, 1994,- 367 с.

3. Кант И. Критика чистого разума. М.:Эксмо, 2016,-736 с.

4. Фрейд 3. Психология масс и анализ человеческого «Я»/пер. с нем //ЯМ Когана. СПб.: Издательская группа «Азбука-классика». - 2010.

5. Хайдеггер М. К вопросу о назначении дела мышления // Личность. Культура. Общество. 2007. Вып. 4 (39). — С. 61-71.(перевод А. Н. Портнова)

6. Шопенгауэр А. Мир как воля и представление. Издательство «АСТ» - 2020, 672 с

7. Юнг Карл Густав. Синхронистичность : [Сборник: Пер. с англ.] М.: РЕФЛ-бук; Киев : Ваклер, 1997 